\section{Endoscopic Findings of an Excessively Compressed Interwoven Nitinol Supera Stent}

Makoto Sugihara, MD, PhD;

Shin-ichiro Miura, MD, PhD

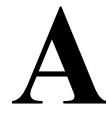

n 84-year-old woman who presented with a nonhealing ulceration on a left toe despite treatment for several months was admitted to hospital. In the first session, the patient underwent endovascular treatment (EVT) for chronic total occlusion of the left superficial femoral artery with severe calcification, and a Supera stent $(5.5 \times 150 \mathrm{~mm})$ (SUPERA ${ }^{\mathrm{TM}}$ stent, Abbott Vascular, Santa Clara, CA, USA) was deployed. After the stent was released from its sheath, compression of the Supera stent was observed on angiography. Subsequently, post-dilatation was performed with a $6.0 \times 150$-mm high-pressure balloon (SHIDEN HP®, KANEKA Medics, Osaka, Japan). Final angiogram and intravascular ultrasound indicated an acceptable result. On high-resolution angioscopy (Forwardlooking $\AA$, OVALIS, Osaka, Japan) 1 week after EVT, the Supera stent was compressed, with the appearance of a spider nest (Figure A). It had the appearance of a spider web, i.e., the wires constituting the stent intertwine each other. Even though the compression was mild and uniform (Figure B,C), the wire of the Supera stent protruded into the vessel lumen. Given that these lesions will not be endothelialized, the risk of a thrombotic event will persist.

The unique design of the Supera stent provides strong radial force with conformability that is clearly different from that of other currently available endovascular stents. Given the interwoven design of this stent and the unique delivery system, the stent may be released elongated, compressed or the normal length depend on deployment of a stent. When this stent is deployed with elongation, primary patency is decreased, compared with normal or compressed deployment. ${ }^{1}$ Thus, we aimed to deploy by normal or shorten length in the present case. Compression can be produced if the delivery system is pushed excessively in order to avoid elongated deployment. In addition, Banerjee et al reported that stent thrombosis with a Supera stent occurred at a fixed frequency. ${ }^{2}$ The present endoscopic findings suggest 1 possible explanation for thrombotic events with a Supera stent.

\section{Disclosures}

The authors declare no conflicts of interest.

\section{References}

1. Garcia LA, Rosenfield KR, Metzger CD, Zidar F, Pershad A, Popma JJ, et al; SUPERB investigators. SUPERB final 3-year outcomes using interwoven nitinol biomimetic Supera stent. Catheter Cardiovasc Interv 2017; 89: 1259-1267.

2. Banerjee S, Sarode K, Mohammad A, Gigliotti O, Baig MS, Tsai S, et al. Femoropopliteal artery stent thrombosis: Report from the Excellence in Peripheral Artery Disease Registry. Circ Cardiovasc Interv 2016; 9: $\mathrm{e} 002730$.

Received December 26, 2019; revised manuscript received February 3, 2020; accepted February 18, 2020; J-STAGE Advance Publication released online March 27, 2020 Time for primary review: 26 days

Department of Cardiology, Fukuoka University School of Medicine, Fukuoka, Japan

Mailing address: Shin-ichiro Miura, MD, PhD, Department of Cardiology, Fukuoka University School of Medicine, 7-45-1 Nanakuma, Jonan-ku, Fukuoka 814-0180, Japan. E-mail: miuras@cis.fukuokau.ac.jp

ISSN-1346-9843 All rights are reserved to the Japanese Circulation Society. For permissions, please e-mail: cj@j-circ.or.jp

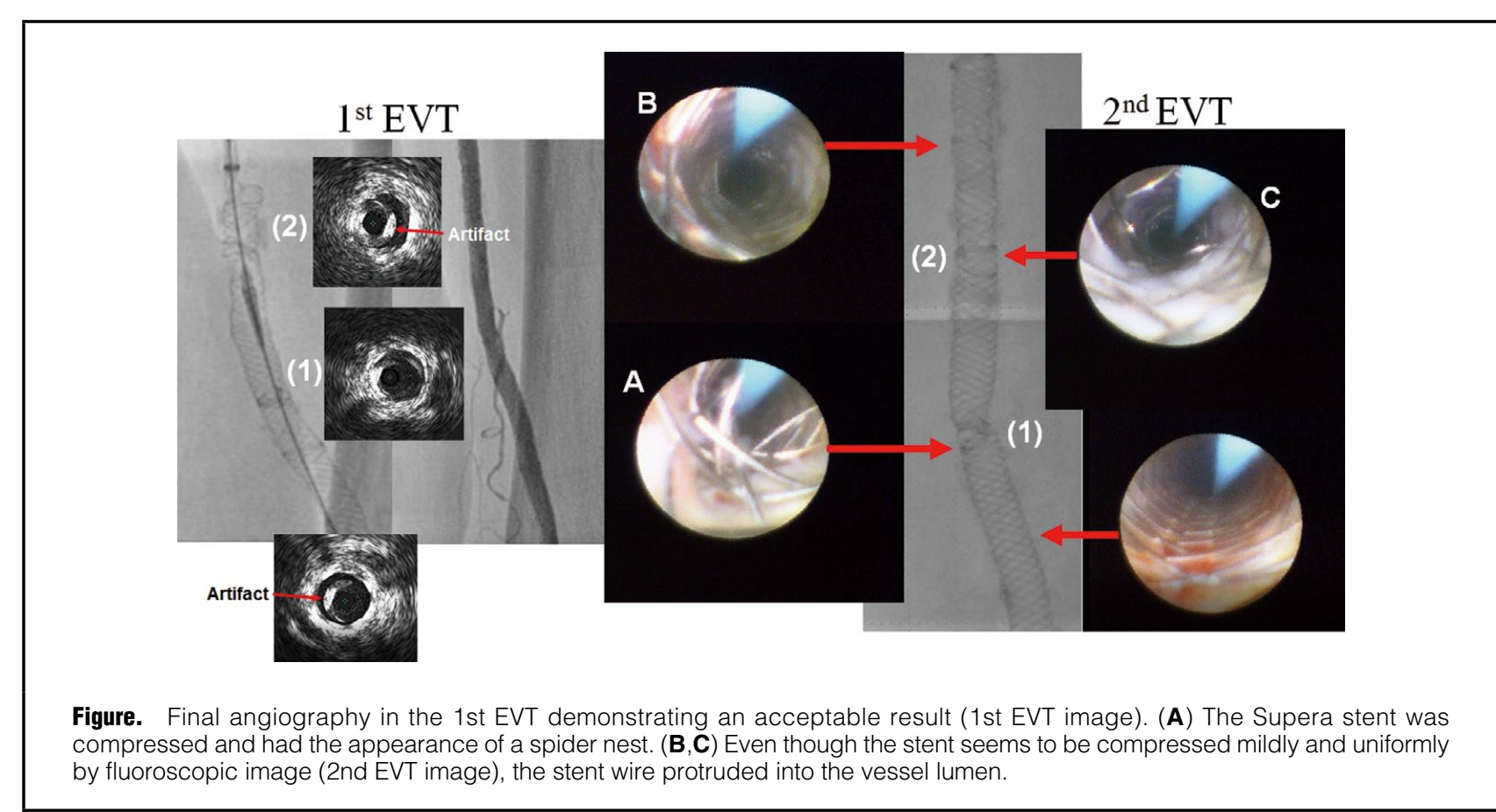

